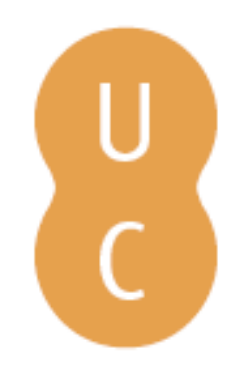

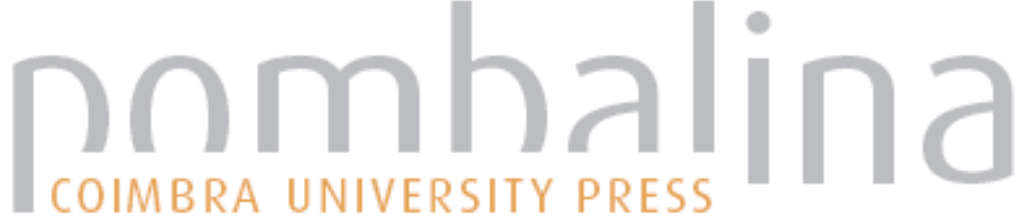

\section{Representações da água na celebração de um enlace real: o carme Proteu de Manuel da Costa}

\author{
Autor(es): $\quad$ Marques, Susana Hora \\ Publicado por: Imprensa da Universidade de Coimbra \\ URL \\ persistente: URI:http://hdl.handle.net/10316.2/45107 \\ DOI: $\quad$ DOI:https://doi.org/10.14195/978-989-26-1568-4_12 \\ Accessed : $\quad$ 26-Apr-2023 07:50:49
}

A navegação consulta e descarregamento dos títulos inseridos nas Bibliotecas Digitais UC Digitalis, UC Pombalina e UC Impactum, pressupõem a aceitação plena e sem reservas dos Termos e Condições de Uso destas Bibliotecas Digitais, disponíveis em https://digitalis.uc.pt/pt-pt/termos.

Conforme exposto nos referidos Termos e Condições de Uso, o descarregamento de títulos de acesso restrito requer uma licença válida de autorização devendo o utilizador aceder ao(s) documento(s) a partir de um endereço de IP da instituição detentora da supramencionada licença.

Ao utilizador é apenas permitido o descarregamento para uso pessoal, pelo que o emprego do(s) título(s) descarregado(s) para outro fim, designadamente comercial, carece de autorização do respetivo autor ou editor da obra.

Na medida em que todas as obras da UC Digitalis se encontram protegidas pelo Código do Direito de Autor e Direitos Conexos e demais legislação aplicável, toda a cópia, parcial ou total, deste documento, nos casos em que é legalmente admitida, deverá conter ou fazer-se acompanhar por este aviso.

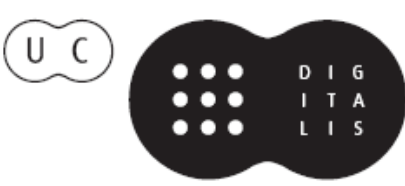




\section{O melhor é a água}

\section{Da antiguidade clássica aos}

nossos dias

José Luís Brandão \& Paula Barata Dias (coords.) 


\title{
REPRESENTAÇÕES DA ÁGUA NA CELEBRAÇÃO DE UM ENLACE REAL: o Carme Proteu de Manuel da Costa ${ }^{1}$ (Representations of Water at the Celebration of a Royal Wedding: the carmen Proteu by Manuel da Costa)
}

\author{
Susana Hora Marques (smp@fl.uc.pt) \\ Centro de Estudos Clássicos e Humanísticos ${ }^{2}$ \\ Universidade de Coimbra \\ orcid.org/0000-0002-4432-2517
}

\begin{abstract}
Resumo - Manuel da Costa, jurista português do século XVI e poeta novilatino, celebra o enlace do príncipe João e da princesa Joana no epitalâmio Proteu, aproveitando a ocasião para elogiar diversas figuras eminentes. Num momento em que o mar abria a Portugal e ao mundo novas paragens e culturas, o motivo da água ocupa lugar de destaque no poema, assumindo diferentes contornos, ora alusivos a divindades que habitam no pélago imenso, ora reveladores de espaços geográficos, ora de embarcações que sulcam a superfície líquida, ora expressivos da autoridade humana.

Palavras-chave - Manuel da Costa, epitalâmio, água.
\end{abstract}

Abstract - Manuelda Costa, Portuguese magistrate and Neo-Latin poet from the 16 th century, consecrates the marriage of Prince João to Princess Joana in the epithalamium Proteus, a poem that also extols several prominent figures. At a time when new maritime routes opened up new cultures and lands to Portugal and the rest of the world, the water element appears as a salient feature in the poem, assuming different forms, either in relation to the deities that inhabit the sea, the revelation of geographic territories or the vessels sweeping across the seas, as well as the affirmation of human authority.

Keywords - Manuel da Costa, epithalamium, water.

A índole marinheira do "peito ilustre lusitano"3 e o espírito aventureiro e conquistador deste povo fronteiriço ao mar, impulsionado pelos seus reis, suscitaram particular expressão laudatória na literatura portuguesa do século XVI, como se sabe, mas também entre poetas novilatinos como António Gouveia, António de Cabedo, Diogo de Teive, Francisco de Macedo, Manuel da Costa, Miguel de Cabedo, entre outros.

\footnotetext{
${ }^{1}$ Este trabalho retoma partes do que foi apresentado no Congresso Internacional $A$ recepção dos clássicos em Portugal e no Brasil (Coimbra, 29-31 de maio de 2013) e posteriormente publicado em Silva e Augusto 2015.

2 Trabalho desenvolvido no âmbito do projeto UID/ELT/00196/2013, financiado pela FCT - Fundação para a Ciência e a Tecnologia.

${ }^{3}$ Camões, Os Lusíadas I, estr. 3, v. 5.
} 
Na verdade, a produção de textos latinos no Portugal de Quinhentos testemunha o gosto pela exaltação e pelo grandioso, sobremodo visível no louvor permanente da expansão ultramarina portuguesa, geradora de um ambiente de epopeia inebriante e incrementador do estímulo a feitos ilustres por parte de governantes e governados ${ }^{4}$. Recorrendo ao paradigma clássico, os poetas novilatinos compõem odes, epitalâmios, longos poemas heroicos, elegias, epigramas, servindo-se com frequência do hexâmetro datílico ou do dístico elegíaco, numa variedade de produções em boa parte reunidas e publicadas por António dos Reis e por Manuel Monteiro no Corpus Illustrium Poetarum Lusitanorum qui latine scripserunt, obra em oito tomos, dada a lume em 1745. Muitos desses textos revestem-se de "valiosa informação cronológica, genealógica, social (...), num impressionante estendal de erudição mitológica, histórica, artística e cultural", como bem sublinha A. Costa Ramalho a propósito do epitalâmio que Cataldo Parísio Sículo dedica a D. Álvaro de Portugal por altura do casamento de sua filha, D. Beatriz, com D. Jorge, filho de D. João $\mathrm{II}^{5}$.

Manuel da Costa, hábil cultor das Musas ${ }^{6}$ e jurista ilustre dessa época, escreve dois epitalâmios, ambos em hexâmetro: o primeiro (1552), consagrado ao enlace de D. Duarte, filho do rei D. Manuel I, com D. Isabel, filha de D. Jaime, IV Duque de Bragança; o segundo (1553), celebrativo do casamento entre o príncipe João, herdeiro de D. João III de Portugal, e a princesa Joana de Castela, filha de Carlos $V^{7}$ - deste último, mais breve, se ocupa o presente estudo.

Poesia de circunstância, usualmente escrita em hexâmetro, o canto nupcial é um género que encontra cultores na tradição clássica, como se sabe: Safo, Teócrito, Catulo, Estácio, Claudiano são alguns dos autores que contam com epitalâmios entre as suas produções literárias, exaltando os noivos ou desejando-lhes ilustre descendência.

No carme Proteu, sobre as núpcias do príncipe João, Manuel da Costa elogia com especial ênfase o monarca reinante e diversos magnates lusitanos, bem como o imperador do reino vizinho, Carlos $\mathrm{V}$, em versos onde o motivo da água surge repetidamente, entrelaçado com uma temática de cariz amoroso.

${ }^{4}$ Sobre a expansão ultramarina portuguesa como motivo de exaltação para os autores novilatinos de Quinhentos, cf. e.g. Matos 1991.

${ }^{5}$ Ramalho 1988: 25-26.

${ }^{6}$ A propósito da biobibliografia de Manuel da Costa, cf. e.g. Marques 2005.

7 Outros autores portugueses cantaram estas núpcias, de suma importância para o assegurar da sucessão dinástica portuguesa: Miguel de Cabedo e Diogo de Teive em latim; António Ferreira em vernáculo.

A alegria de D. João e de D. Joana não duraria muito, como é sabido, já que cerca de um ano depois, a 2 de janeiro de 1554, o príncipe viria a falecer, deixando a esposa grávida de um filho, D. Sebastião. Sobre o tratamento do tema da morte de D. João na poesia quinhentista, cf. Soares 2010. 
Num momento em que o mar imenso abria aos Portugueses e ao mundo novas e fascinantes paisagens e culturas, a partir da foz do Tejo, como Camões recorda n' Os Lusíadas ${ }^{8}$, o elemento líquido assume diferentes contornos no poema de Manuel da Costa, ora alusivos a divindades que nele habitam, ora reveladores de espaços geográficos, ora de embarcações que sulcam a superfície líquida, ora expressivos da autoridade humana.

Os versos de abertura do epitalâmio, reminiscentes do canto IV das Geórgicas virgilianas (vv. 387 sqq.), localizam desde logo a morada do divino Proteu nas águas dos Cárpatos, concentrando auspiciosamente a atenção do leitor nessa divindade marinha, detentora do dom da profecia e polimórfica como a própria água, e que ocupará lugar de destaque na estrutura do poema9 ${ }^{9} \mathrm{Na}$ verdade, embora afastado das plagas hispânicas, é o próprio Proteu quem descreve os festejos do casamento real, em 147 dos 179 versos que constituem a totalidade do carme ${ }^{10}$. O prestígio do narrador traduz o relevo do enlace, conferindo-lhe bom augúrio, sem deixar de evocar também a importância concedida ao mar na história lusitana. O recurso a múltiplos termos para designar o pélago é sugestivo do convívio permanente do povo português com essa realidade mais ou menos profunda e enigmática - cf. e.g. fretum, altum, undas, ponto, pelago, maris, aequora.

O discurso do deus surge em resposta à curiosidade das Nereides perante uma viva agitação que testemunham no mar dos Cárpatos: um cortejo aparatoso se prepara rumo ao Ocidente ${ }^{11}$. Vénus, Cupido, um Himeneu maior que o costume, Neptuno, Tritão contam-se entre os distintos participantes da comitiva, que reúne assim divindades do amor, naturalmente associadas à união dos príncipes, e deuses marinhos cuja presença honrosa é ora ilustrativa da identidade marinheira do povo lusitano e do momento áureo de expansão marítima que o mesmo vivia, ora representativa de uma fecundidade almejada para o trono lusitano (cf. o entendimento da água como símbolo de vida e de fertilidade). Entidades femininas e masculinas envolvem-se pois, indistintamente, na celebração, congregando atributos diversos num objetivo comum, marcado pela fusão entre beleza, amor, musicalidade, poderio. A aliança divina é prenunciadora de um final feliz para um casamento muito desejado pela coroa portuguesa, em risco

${ }^{8} \mathrm{IV}, 84,1-5$.

${ }^{9}$ Cf. vv. 1-4: Est in Carpathiis scopulus late arduus undis, / Nota senis Protei sedes, de uertice cuius/Prospicit egressas uicina ad littora phocas, / Reddit et ambiguis diuina oracula rebus.

${ }^{10}$ A propósito da narração de Proteu, Miguel Mora 1999: 136 recorda o "epílio de Proteu", no canto VII dos Punica de Silo Itálico, "onde o idoso visionário relata às ninfas o juízo de Páris e anuncia as vicissitudes da guerra, até à destruição de Cartago".

${ }^{11} \mathrm{O}$ esplendor do cortejo observa-se não apenas pela dignidade dos deuses que o constituem, como também pelas riquezas que transportam consigo, refletidas em substantivos como diuitiis, fastu e em adjetivos do tipo aureo. 
de se ver sem sucessor ao trono de D. João III, devido às mortes sucessivas de seus filhos.

Em sintonia com as divindades, múltiplas espécies do universo marinho, por certo familiares aos nautas portugueses, cooperam na festa: delfins substituem os habituais cisnes condutores do carro de Vénus; dorsos imensos de baleia transportam parte da comitiva; diversos peixes em geral se mostram animados com a comemoração.

Apontamentos cromáticos, definidores da tonalidade cerúlea das águas, e indicações sonoras, a evidenciar o anúncio do himeneu através da famosa concha de Tritão, conjugam-se com o cenário de movimento apresentado, numa simbiose de sensações expressiva da vitalidade do mar, do seu colorido, da sua musicalidade.

Em momento de festa e de alegria, valorizam-se os elementos positivos relacionados com a água, passando-se ao largo da evocação dos perigos que a mesma também pode representar e que um país de marinheiros como Portugal não deixou de experimentar.

Guiados pelas palavras de Proteu, somos transportados do plano mítico para o humano, dois domínios que se cruzam ao longo do poema, numa associação prestigiosa para os mortais, patrocinados pelos deuses.

A revelação do local das núpcias recorda, num primeiro momento, a configuração do mapa de Portugal, vizinho da costa, na extremidade da Península Ibérica: casam-se nas plagas ocidentais, lá por onde a vitoriosa Hispânia termina no magno Oceano ${ }^{12}$. Em seguida, porém, os traços definem uma geografia mais precisa, situando o casamento na cidade que recebeu de Ulisses o nome, a ínclita Lisboa, a qual, com as naus dos Lusíadas, tudo submete ${ }^{13}$. A delimitação do espaço proporciona ocasião para exaltar a expansão dos Portugueses, dominadores de África e do Oriente a partir da ilustre capital portuguesa.

A população lisboeta, por sua vez, não se furta a esforços para mostrar o contentamento experimentado, numa participação que constitui um tópico panegírico mencionado por Curtius 1955: terra firme e superfície líquida aliam-se nos festejos, ora com inúmeros espetáculos, ora com embarcações ornadas na popa, a darem visibilidade às emoções sentidas.

É neste ambiente propício e faustoso que D. João III em pessoa se dirige de Lisboa à outra margem do Tejo, o Barreiro, numa nau magnificamente equipada ${ }^{14}$ e acompanhado por diversas figuras eminentes, no intuito de conduzir para a cidade < de Lisboa> Joana, destinada a seu filho, Joã $0^{15}$. Atravessar o rio Tejo surge

\footnotetext{
${ }^{12} \mathrm{Vv.} \mathrm{33-35:} \mathrm{...iunguntur} \mathrm{in} \mathrm{oris/} \mathrm{Occiduis,} \mathrm{qua} \mathrm{se} \mathrm{uictrix} \mathrm{Hispania} \mathrm{magno/} \mathrm{Terminat} \mathrm{Oceano.}$

${ }^{13}$ Vv. 35-36: Sed enim de nomine Vlixes/Dicta urbs, Lusiadum ratibus quae cuncta subegit.

${ }^{14}$ V. 59: ... mire instructam nauim...

${ }^{15}$ Vv. 72-73: ... Ioannam ut nato secum deducat in urbem/Ioanni.
} 
assim como uma exigência natural na rota determinada para a princesa oriunda do reino vizinho se unir pelo casamento ao filho do soberano português: as doces e fluentes águas do Tejo abrem caminho a uma promessa de fecundidade para a coroa portuguesa.

O percurso de regresso à cidade que recebeu o nome de Ulisses proporciona a oportunidade a Manuel da Costa para se referir elogiosamente a D. João III, através do recurso a uma imagem náutica: as águas revoltas, os ares sibilantes, as ondas espumosas acalmam por efeito da distinta e respeitável presença do rei. A tranquilidade sobrepõe-se ao tumulto, espelhando a sintonia da natureza com o momento de paz festiva vivido; apenas ao Zéfiro é permitido propagar uma brisa ligeira, garante de uma navegação facilitada e serena até ao destino ${ }^{16}$.

O cruzamento do Tejo constitui a ocasião para o encómio da beleza da noiva, comparada a figuras míticas às quais supera, numa valorização dos contemporâneos própria dos epitalâmios e comum desde a Antiguidade clássica. De modo expressivo, as figuras femininas com as quais se estabelece o confronto - a jovem princesa feácia Nausícaa e a divina Tétis - são enquadradas em paisagens litorais, singularizando-se esses ambientes como locais favorecedores de encontro: tão bela Nausicaa, filha de Alcinoo, não viu outrora Ulisses entre as Ninfas, na costa dos Feaces (...); a nossa querida Tétis, quando devia ser confiada ao marido, o rei Peleu, não pisou com tal garbo as areias da Tessália ${ }^{17}$. Se no caso das personagens míticas com as quais é estabelecido o paralelo se designam os heróis que completam o par respetivo, a princesa de Castela é porém destacada na sua individualidade, como acontecerá de resto nos versos finais do poema em relação ao jovem príncipe: Manuel da Costa privilegia a distinção dos noivos e, em particular, a viagem que garante a sua união.

$\mathrm{Na}$ frota que conduz $\mathrm{D}$. Joana ao seu amor salienta-se a proveniência do séquito feminino que a acompanha, através da alusão metonímica aos cursos de água que banham os seus locais de origem, o Tejo, o Ebro e o Bétis, atual Guadalquivir, nascidos respetivamente no centro, no norte e no sul de Espanha ${ }^{18}$ - na companhia da filha de Carlos V Proteu vê mulheres oriundas de todo o reino vizinho, que se manifesta igualmente exultante com a união.

A travessia oferece ainda motivo para recordar a mítica armada de Áulide,

${ }^{16}$ Cf. vv. 86-92: Tollitur interea uentis mare, sibilat aura,/Voluuntur cano spumantes uellere fluctus:/ Sed tamen ornatis tenuit cum classibus altum/ Ioannes; illi posuerunt flamina uenti/ Actutum, et supplex iacuit sine murmure pontus. Tantum uni Zephyro permissum est leniter undas/ Pacati crispari maris.

17 Vv. 99-102: Talem inter Nymphas Phaeacum in littore quondam/ Nausicaam, Alcinoo genitam, non uidit Vlixes./...Aemonias pressit non talis arenas/Nostra Thetis, Regi Peleo tradenda marito. Cf. Od. 6; Cat. 64.

18 A indicação da proveniência das personagens através dos rios identificativos dos respetivos locais de origem surge também a propósito do Bispo de Arganil, designado como o bispo da cidade situada junto ao Mondego (v. 83). 
na sequência da alusão aos ornamentados e vistosos navios portugueses, com velas de seda e de púrpura ${ }^{19}$ a testemunhar o momento áureo da expansão do reino por longínquas paragens. Promissoras de uma viagem tranquila até ao destino, as velas colhem as brisas ligeiras que sopram favoravelmente da popa. O conhecimento do universo naval do povo lusitano é notório nas designações múltiplas usadas para referir as embarcações que cruzam a superfície líquida ou partes que as constituem (cf. e.g. ratibus, puppes, nauim, pinus, carinas, uelorum, cymbae). $\mathrm{O}$ confronto com a Antiguidade clássica, por sua vez, permite uma vez mais superlativar os contemporâneos: desta feita, o esplendor das naus que acompanham o navio real supera admiravelmente o da imensa e poderosa frota grega outrora retida em Áulide ${ }^{20}$, quer em fausto, quer em número.

A ocasião presta-se também à descrição das insígnias do pai da noiva, as águias da Casa da Áustria e os leões de Leão, exibidas nas embarcações e tradutoras da sua identidade e poderio, abrindo caminho a um novo momento laudatório no poema: enaltece-se a família real da jovem, na figura de Carlos $\mathrm{V}$, pelas vitórias que o mesmo obteve (o triunfo sobre os Franceses na batalha de Pavia, a tomada de Roma, a vitória sobre os Turcos e sobre os Alemães, considerados hereges). O elogio transporta o leitor, por instantes, para um cenário em que a água surge como palco de confrontos, heroicamente vencidos pelo pai de D. Joana: foi nas margens do Danúbio que ele derrotou Solimão II, sultão dos Turcos, em defesa da fé católica. A valia de Carlos V e do seu exército pressupõe também a menção a outro rio da Europa central, o Elba: antes dificilmente navegável, deu-se por vencido diante das embarcaçôes ligeiras e dos Espanhóis que o passavam a nado ${ }^{21}$. O registo destes cursos de água, testemunhos do poder do soberano, permite a Manuel da Costa gizar o roteiro definidor das conquistas daquele, através de elementos que integram a moldura dos países respetivos e que os caracterizam.

Entrelaçando passado próximo e realidade festiva do momento, é ainda na referência a um rio, desta feita àquele que banha e desagua na cidade de Lisboa, evidenciando-se como traço marcante da sua identidade, que o autor se concentra: nascido em terras do reino confinante e terminando junto ao mar donde os Portugueses se lançaram para os Descobrimentos, o próprio Tejo simboliza as relações entre reinos limítrofes, consolidadas pelas sucessivas alianças matrimoniais entre pessoas das famílias reais de Portugal e de Espanha ${ }^{22}$.

${ }^{19}$ Vv. 108-109: Conspicuae filis bombycum et murice pinus/ Regalem stipant nauem.

${ }^{20} \mathrm{Cf}$. Eurípides, Ifigénia em Áulide, vv. 231-302.

${ }^{21}$ Vv. 127-129: ...utque Hispanis tranantibus Albis/ Spumeus et leuibus vix nabilis ante carinis/Cesserit...

${ }^{22} \mathrm{Cf}$. os casamentos de D. Manuel I com D. Isabel e com D. Maria, ambas filhas dos Reis Católicos, e ainda o seu terceiro matrimónio com D. Leonor, irmã de Carlos V; o casamento de D. João III com D. Catarina, irmã também do soberano do reino vizinho; o de Carlos V 
O Tejo destaca-se também na própria realidade quotidiana portuguesa, representando um elo de ligação entre as suas margens, o Barreiro e Lisboa, irmanadas pela navegação constante de embarcações que o sulcam e o convertem em recurso indissociável do dia a dia da população, ajustada às condições impostas pela geografia.

Para honrar D. Joana, o Tejo esparze por toda a parte o ouro que esteve oculto durante tantos anos pelas areias brilhantes ${ }^{23}$, pondo a descoberto uma característica comum a outros rios, como o Hermo, atual Gediz, e mencionada por vários autores (cf. e.g. Cat. 29, 19; António Ferreira, "Ode aos príncipes D. João e D. Joana”): a natureza participa na exibição do esplendor da cidade que recebe a noiva distinta, conferindo ao curso de água que a atravessa uma tonalidade dourada, apropriada às circunstâncias.

Das profundezas do Tejo se mostram as Náiades, com um presente para a noiva, um puluinar geniale evocativo do oferecido outrora à divina Tétis (cf. Cat. 64, 47 sqq.); as cenas que o entretecem, porém, são adequadamente alusivas à História de Portugal, com particular destaque para o nascimento do monarca reinante, D. João III, e contribuem para o tom laudatório do carme ${ }^{24}$.

Quase a findar o poema, elementos sonoros e visuais anunciam o termo da navegação, aclamando solenemente a noiva que chega ao porto de destino: disparos de canhões, em terra e no mar, e o fumo daí resultante são expressivos da festa, do entusiasmo, da alegria das gentes e do reino.

As palavras de Proteu fazem ainda uma breve incursão ao interior do palácio, onde o noivo, aguardando o amor, se encontra na companhia da mãe, a rainha $\mathrm{D}$. Catarina, cuja beleza, nobreza e dotes de alma rivalizam com a própria Anfitrite, senhora do mar. Num texto tão marcado pelo elemento líquido, é natural a opção por este paralelo, elogioso para a rainha portuguesa.

A garantia da chegada de D. Joana a Lisboa, confirmação de aliança entre os reinos peninsulares e promessa de descendência futura para a pátria portuguesa, permite que o poema acabe sem o encontro efetivo dos noivos, não se descrevendo, nem em breves versos, a cerimónia do casamento: Manuel da Costa, poeta áulico, privilegia a exaltação de personagens ilustres e de aspetos relacionados com o momento áureo da expansão portuguesa, em detrimento do relato de um enlace que se afigurava seguro.

A par da informação sobre a chegada da noiva ao destino, onde a aguardava o ansioso príncipe, a própria natureza convida à suspensão do canto divino: a

com a irmã de D. João III, D. Isabel; os dos filhos de Carlos V, D. Joana e Filipe II, com D. João e D. Maria, respetivamente, progénie de D. João III de Portugal.

${ }^{23}$ Vv. 134-135: ... aurumque tot annis/ Occultum, rutilis unlgo dispergit arenis.

${ }^{24} \mathrm{Cf}$. vv. 136 sqq. A descrição de acontecimentos por meio de objetos é um processo épico já usado nos Poemas Homéricos, como se sabe (cf. Il. 18. 478 sqq.). 
noite que surgia nos Cárpatos instigava Proteu a descer para a cristalina morada, circunstância que Manuel da Costa aproveita para desenhar o quadro de fim de dia com que conclui o seu carme - e já a noite cobria o céu dum manto escuro; as águas do mar resplandeciam com os raios da Lua ${ }^{25}$. Sugestivamente, o poema abre e termina com a referência ao universo marinho, procedimento expressivo da relevância do mesmo na História de um país bem conhecedor do ambiente aquático. A nota final é a de um brilho que se adequa ao momento de esplendor do reino lusitano e do enlace real.

Ao longo da composição, o elemento líquido desenha-se sobretudo como colaborador dinâmico numa viagem serena, com um destino que se prevê ditoso e apoiado pelos deuses.

A água é mar salgado, propício a um país de marinheiros, corporizando-se em divindades que povoam o pélago imenso; a água é rio doce, favorecedor da navegação, do cruzamento de gentes e culturas e promissor de fecundidade; a água é reflexo do poderio de homens insignes; a água é elo de aproximação entre noivos ilustres, a caminho de uma vida nova.

$* * *$

\section{Ad Ioannem et Ioannam, Principes Lvsitaniae Serenissimos,}

\section{PROTEVS*}

Est in Carpathiis scopulus late arduus undis,

Nota senis Protei sedes, de uertice cuius

Prospicit egressas uicina ad littora phocas,

Reddit et ambiguis dinina oracula rebus.

Hic illum (sic fama refert) uidere puellae

Nereides similem attonito atque immota tenentem

Lumina; formosae quem candida filia Costae,

Iana, potens cantu morientes uincere cygnos,

Aggreditur: Venerande senex, qui pectore in isto

Transacta, et quae sunt, uenturasque saecla recondis:

Cum nuper Cyprias legeremus in aequore conchas, Lunae....

${ }^{25}$ Vv. 177-178: ...Nam iam fusco uelebat amictu/ Nox coelum; radiis splendebant aequora 
Diuitiis onerata maris fastuque superbo,

Visa Venus sulcare fretum. Cum matre Cupido

Ibat ouans, duplici telo spectabilis aureo:

Frenatos supplere uicem delphinas olorum

Cernere erat. Veneris famulas immania terga

Balaenae ac solito maiorem Hymenaea uehebant.

Aligeri nando uariis in piscibus ibant

Ludentes circum pueri, qui tempora myrto

Velati, dederant collo pendere pharetras.

Quin etiam Neptunus equis per caerula uectus

Dicitur Oceanum, ac Phoebi petiisse cadentis

Littora, praemissumque ferunt Tritona canorum,

Qui totum inflata concha circumsonet aequor

Diuinas taedas et felices Hymenaeos.

Dic igitur, quinam Sponsi, quo sanguine creti,

Quoue loco tanti thalami celebrentur honores?

Hic etenim nos cura tuae mandata senectae

Detinuit, festas licuit neque cernere pompas.

Tunc Proteus: Gemini flores, decora inclita mundi,

Progeniti iunenes, quorumque parentibus orbis

Nil melius, nil maius habet: iunguntur in oris

Occiduis, qua se uictrix Hispania magno

Terminat Oceano. Sed enim de nomine Vlixes

Dicta urbs, Lusiadum ratibus quae cuncta subegit,

Finibus a Libycis Orientis ad usque beati

Ignotas terras, grandi molimine uires

Explicat, ut digno, quem juste ambiuit, honore

Has possit celebrare faces. Per compita passim

Eduntur festis centum spectacula ludis:

Mille coronatae ludunt ad littora puppes.

Hic gens Lusiadum, qua nulla fidelior usquam,

Obseruat Reges; hodie, quascumque parauit,

Exultans profundit opes: et uestibus aurum

Aptat, et elato bacata monilia collo.

Hic Castellani, pretioso uellere Serum

Induti, laetas atollunt uertice cristas.

Nec tantum affectus animi praediuite cultu

Extremae Hesperiae certant ostendere gentes.

Ipsa etiam lasciuit humus: quam germine florum

Vernantem, ut Tauri si cornua Sole calerent,

Mirantur, nullosque imbres, atque aethera purum, 
Mutatasque uices anni: nam tempora ueris

Laeta quis in plunio uidit ridere Decembri?

Hanc demum, qua Ioanni Ioanna marito

Tradenda est, niueo Lachesis de stamine lucem

Ducit, et egregio condonat lumine Titan.

Iam mire instructam nauim, quae caerula uerrit

Auro intertexto, conscendit auunculus idem,

Ioannaeque socer, Regum iustissimus omnium, Ioannes, Lusio induxit qui saecula regno Aurea, nunc hominum porro commercia taxat Legibus, ut ferreae pereant uestigia fraudis.

Illum habitu insignem regali ipsaque uerendum

Maiestate, tremor Libyae, uirtutibus ingens, Fraterni columen regni, Ludouicus, et omnes Hesperiae ante Duces uasta ditione, superbus Theudosius, proceresque alii comitantur euntem Tendit in aduersam Barreri littoris oram, Alta serenato praetendens gaudia uultu, Ioannam ut nato secum deducat in urbem Ioanni. Pro quo sollemnia uerba mariti Concepit, rari Legati munere functus, Tauorea de gente ducum Laurentius unus, Dilectus Musis, Tydeoque animosior armis.

Virginis eiusdem merito custodia summa, Extremis patriae Castellae a finibus usque, Propter laudatas generosi Principis artes, Auerio est comissa Duci, de stirpe creato Ioannis, quem fama uehit super astra, Secundi.

Ducit et immensis Comes Arganilius illam Sumptibus, ad Mondam posita qui Praesul in urbe, Fulmineo tonat ore pius monituque potenti Terrenos animos rapit in penetralia Coeli.

Tollitur interea uentis mare, sibilat aura, Voluuntur cano spumantes uellere fluctus:

Sed tamen ornatis tenuit cum classibus altum Ioannes; illi posuerunt flamina uenti Actutum, et supplex iacuit sine murmure pontus.

Tantum uni Zephyro permissum est leniter undas

Pacati crispare maris. Ne singula narrem,

Ecce triumphali uehitur super aequora pompa

Cum socero, Caroli Quinti dignissima proles, 
Ioanna. O qualem uultum, quae lumina cerno,

Nereides, quantum Augusto decus emicat ore:

$V t$ crines reuoluta aureos gemmisque coruscis

Irradians, uenit in niuea pulcherrima ueste.

Talem inter Nymphas Phaeacum in littore quondam

Nausicaam, Alcinoo genitam, non uidit Vlixes.

Quid loquor? Aemonias pressit non talis arenas

Nostra Thetis, Regi Peleo tradenda marito.

Cerno etiam quas unda Tagi, quas flumen Iberum,

Quas aluit Baetis, specioso corpore Nymphas

Ioannae. Nimiumque oculos deiecta refulget

Syluia, quam pridem colit et facit ille colendam

Syluius, Hispanis longe celeberrimus oris.

Conspicuae filis bombycum et murice pinus

Regalem stipant nauem. Non Aulide plures,

Non sic compositas Danai soluere carinas.

A puppi aspirant aurae uentusque secundus

Aequatas tendit uelorum flatibus alas.

Hic sese ostentant cymbae quae monstra profundi,

Caesareasque aquilas, Castellanosque leones,

Atque Indos referunt prono diademate Reges.

Tum uero innocuae Siculis de rupibus adsunt

Sirenes, Caroli patris quae bella canendo

Perstringunt: Ticini captiuum ad moenia Regem

Gallorum, mox Caesarea uirtute solutum;

Romam illam, rerum dominam, mundique potentem,

Auspiciis etiam inuiti parere coactam;

Danubii ad ripas commisso marte fugatum

Turcarum Dominum immanem, dum Caesaris horret

Fortunam, inuictumque animum, Hispanosque propinquos.

Addunt et captas superatis ciuibus urbes

Ardentis Libyae, debellatosque rebelles

Germanos, utque Hispanis tranantibus Albis

Spumeus et leuibus uix nabilis ante carinis

Cesserit, atque humiles aquilis instrauerit undas

Augusti, refugum uindex quo caederet hostem;

Denique, ut assertum bello sic temperet orbem

Maximus, ut titulos Magnorum excesserit omnes.

Parte alia erumpit salsis Tagus altior undis

Occultum, rutilis uulgo dispergit arenis.

Tum, procedentes e gurgite Naiades aureo, 
Ioannae thalami contextum munus in usum Puluinar geniale ferunt, quo cernere possit Alphonsum Henrici, Lusiosque ex ordine Reges, Maternum genus, et partem pro tempore monstrant Arte noua, et multo ante alias splendore nitentem, In qua Reginae socerum de uentre Mariae Nascentem, insolitis nimbis atque ignibus aether Parturit. Horrentes Afrique Indique Tyranni, Ac uelut exangui spectantes aethera uultu, Ioannem agnoscunt, praedictum a uatibus, edi. Ad partus uirgo propere descendit ab alto Astraea, et Superum deducit ab arce Sorores. Excipit infantem, uiridante insignis oliua, Aurea Pax: cunas motant ad carmina Musae.

Talia dum medio in ponto miranda uidentur,

Vrbs Dominae assurgens subitis Mauortia flammis Fulminat horrendum. Rapido impetu tormentorum Terra tremit: nutant celsae cum moenibus arces;

Confugiunt pauidi materna ad pectora nati.

Responsant pelago naues, atque aera fumo

Inuoluunt, cunctisque uomunt e partibus ignem.

Hos inter mixtos urbis pelagique tumultus,

Sidereus iunenis, patrii spes unica regni,

Ioannes, cui non temere est fatale parentum

Impositum nomen, Catharinae ad strata recumbit, Reginae Matris, cuius formamque genusque Diuinasque animi dotes, me forte canentem Audistis, uolui offensus si quando mouere Inuidiam magnae Dominae maris, Amphitritae.

Multus honos decoris, maiestatisque paternae

In iuuenis facie est. Candens distinguitur auro

Vestis, et in famulo lectis Oriente lapillis.

Iamque ardens primum congressum atque oscula prima Virginis Augustae salienti corde uolutat.

Talis erat, tales animo noluebat amores

Sol olim, nondum prima lanugine malas

Vestitus, Lucisque nouo iam captus amore:

Cum pater omnipotens auspex, et pronuba Iuno,

Coelestes inter Diuos ac Numina ponti,

Ducebant teneram laeta ad connubia Lucem.

Haec Proteus. Nam iam fusco uelabat amictu 
Nox coelum; radiis splendebant aequora Lunae:

Tempus E' in uitreas scopulo descendere sedes.

Laus Deo

*In nuptiis Ioannis, et Ioannae Lusitaniae Principum

carmen CIPL.

\section{Bibliografia}

Curtius, Ernst Robert (1955), Literatura europea y Edad Media latina. Vol. I. Trad. de M. F. Alatorre y A. Alatorre. México.

Marques, Susana (2005), Dois epitalâmios latinos de Manuel da Costa (século XVI). Introdução. Tradução. Notas e comentários. Coimbra.

Matos, Luís de (1991), L'expansion portugaise dans la littérature latine de la Renaissance. Pref. de J. Pina Martins. Lisboa.

Miguel Mora, Carlos de (1999), "As leituras dos humanistas: fontes secundárias de Manuel da Costa”, Agora. Estudos Clássicos em Debate 1: 133-154.

Oliveira, Francisco de, Thiercy, Pascal e Vilaça, Raquel (coords.), (2006), Mar greco-latino. Coimbra.

Ramalho, Américo da Costa (1983), Estudos sobre o século XVI. Lisboa.

Ramalho, Américo da Costa (1988-2000), Para a história do humanismo em Portugal: I (Coimbra, 1988); II (Lisboa, 1994); III (Lisboa, 1998); IV (Lisboa, 2000).

Sánchez-Marín, José (1991-1992), "Caracteristicas de la obra poética de Manuel da Costa”, Humanitas 43-44: 257-274.

Sánchez-Marín,José (1992), "Un epitalamio latino: el carmen Proteus de Manuel da Costa", in Miscelânia de estudos em honra do Prof. A. C. Ramalho. Lisboa, 199-213.

Serrano Cueto, A. (2014), "Historia y ficción poética en la deductio moderna: el largo viaje de la novia en tres epitalamios latinos del siglo XV en honor de la casa de Aragón”, Euphrosyne 42: 67-86.

Serrano Cueto, A. (1996), "La musa latina del jurista português Manuel da Costa: el Ad Ioannem et Ioannam principes Lusitaniae serenissimos Proteus", Excerpta Philologica 6: 207-225. 
Silva, M. F. e Augusto, M. G. (coords.) (2015), A recep̧̧ão dos clássicos em Portugal e no Brasil. Coimbra: 161-172

Soares, Nair de Nazaré Castro (2010, 3a ed.), Diogo de Teive. Tragédia do príncipe João. Coimbra. 